\title{
Common ground as a resource for social affiliation
}

\author{
Nicholas J. Enfield
}

\section{Introduction}

The pursuit and exploitation of mutual knowledge, shared expectations, and other types of common ground (Clark 1996; Lewis 1969; Smith 1980) ${ }^{1}$ not only serves the mutual management of referential information, but has important consequences in the realm of social, interpersonal affiliation. The informational and social-affiliational functions of common ground are closely interlinked. I shall argue in this chapter that the management of information in communication is never without social consequence, and that many of the details of communicative practice are therefore dedicated to the management of social affiliation in human relationships.

Common ground constitutes the open stockpile of shared presumption that fuels amplicative inference in communication (Grice 1989), driven by intention attribution and other defining components of the interaction engine (Levinson 1995, 2000, 2006). Any occasion of "grounding" (i.e., any increment of common ground) has consequences for future interaction of the individuals involved, thanks to two perpetually active imperatives for individuals in social interaction. An informational imperative compels individuals to cooperate with their interactional partners in maintaining a common referential understanding, mutually calibrated at each step of an interaction's progression. Here, common ground affords economy of expression. The greater our common ground, the less effort we have to expend to satisfy an informational imperative. Second (but not secondary), an affiliational imperative compels interlocutors to maintain a common degree of interpersonal affiliation (trust, commitment, intimacy), proper to the status of the relationship, and again mutually calibrated at each step of an interaction's progression. In this second dimension, the economy of expression enabled by common ground affords a public display of intimacy, a reliable indicator of how much is personally shared by a given pair (trio, n-tuple) of interactants. In these two ways, serving the ends of informational economy and affiliational intimacy, to increment common ground is to invest in a resource that will be drawn on later, with interest. 


\section{Nicholas J. Enfield}

\section{Sources of common ground}

A canonical source of common ground is joint attention, a unique human practice that fuses perception and inferential cognition (Moore and Dunham 1995; Tomasello 1999, 2006). In joint attention, two or more people simultaneously attend to a single external stimulus, together, each conscious that the experience is shared. Fig. 1 illustrates a typical, everyday joint attentional scene.

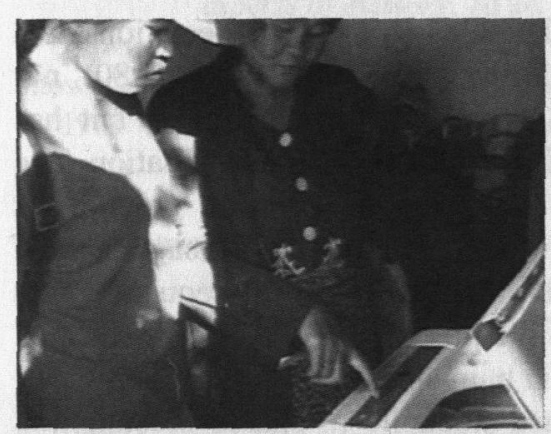

Figure 1.

In this example, the fact that a washing machine is standing in front of these women is incontrovertibly in common ground thanks both to its physical position in the perceptual field of both interactants and to its operating panel being the target of joint attentional hand gestures (Kita 2003; Liszkowski 2006). But common ground is also there when it is not being signaled or otherwise manifest directly. At a personal level, the shared experiences of interactants are in common ground as long as the interactants know (and remember!) they were shared. At a cultural level, common ground may be indexed by signs of ethnic identity, and the common cultural background such signs may entail. One such marker is native dialect (as signaled, e.g., by accent), a readily detectable and reliable indicator of long years of common social and cultural experience (Nettle and Dunbar 1997; Nettle 1999). Suppose I begin a conversational exchange with a stranger of similar age to myself, who, like me, is a native speaker of Australian English. We will each immediately recognize this common native origin from each other's speech, and then I can be pretty sure that my new interlocutor and I will share vast cultural common ground from at least the core years of our linguistic and cultural socialization (i.e., our 
childhoods, when our dialects were acquired). We will mutually assume, for instance, recognition of expressions like fair dinkum, names like Barry Crocker, and possibly even sporting institutions like the Dapto Dogs.

\section{Common ground as fuel for Gricean ampliative inference}

Common ground is a resource that speakers exploit in inviting and deriving pragmatic inference, as a way to cut costs of speech production by leaving much to be inferred by the listener. As Levinson (2000) points out, the rate of transfer of coded information in speech is slow, thanks to our articulatory apparatus. Psychological processes run much faster. This bottleneck problem is solved by the ampliative properties of pragmatic inference (Levinson 2000; cf. Grice 1975). Interpretative amplification of coded messages feeds directly on the stock of common ground, in which we may' include a language's semantically coded linguistic categories (lexicon, morphosyntax), a community's set of cultural practices and norms (Levinson 1995: 240; Enfield 2002: 234-236), and shared personal experience. (This implies different categories of social relationship, defined in part by amount and type of common ground: e.g., speakers of our language, people of our culture, and personal associates of various types; see below.) This logic of communicative economy-intention attribution via inference fed by common ground - is complemented by the use of convention to simplify problems of social coordination (Clark 1996; Lewis 1969; Schelling 1960). Although we have access at all times to the powerful higher-order reasoning that makes common ground and intention attribution possible, we keep cognition frugal by assuming defaults where possible (Gigerenzer et al. 1999; Sperber and Wilson 1995; cf. Barr and Keysar 2004). So, if tomorrow is our weekly appointment (midday, Joe's) we do not have to discuss where and when to meet. The hypothesis that we will meet at Joe's at midday has been tested before, ${ }^{2}$ and confirmed. And we further entrench the convention by behaving in accordance with it (i.e., by turning up at Joe's at midday and finding each other there).

Consider a simple example from everyday interaction in rural Laos, which illustrates common ground from both natural and cultural sources playing a role in inference making. Fig. 2 is from a video recording of conversation among speakers of Lao in a lowland village near Vientiane, Laos. (The corners of the image are obscured by a lens hood.) The image shows a woman (foreground, right; hereafter, Foreground Woman [FW]) 


\section{Nicholas J. Enfield}

who has just finished a complex series of preparations to chew betel nut, involving various ingredients and tools kept in the basket visible in the lower foreground. In this frame, FW is shifting back, mouth full with a betel nut package, having finished with the basket and placed it aside, to her left:

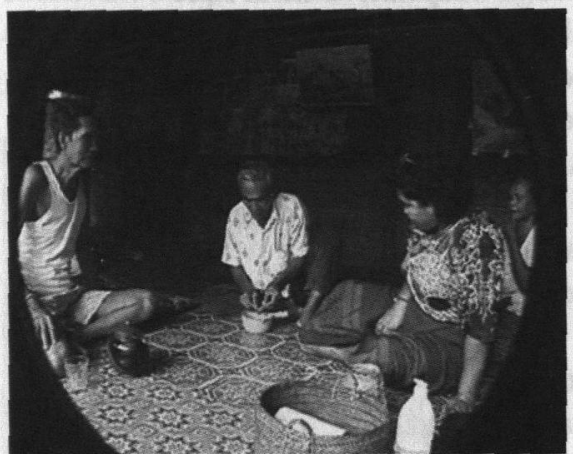

Figure 2.

Immediately after this, the woman in the background, at far right (Background Woman [BW]), moves forward, to reach in the direction of the basket, as shown in Fig. 3a, b.

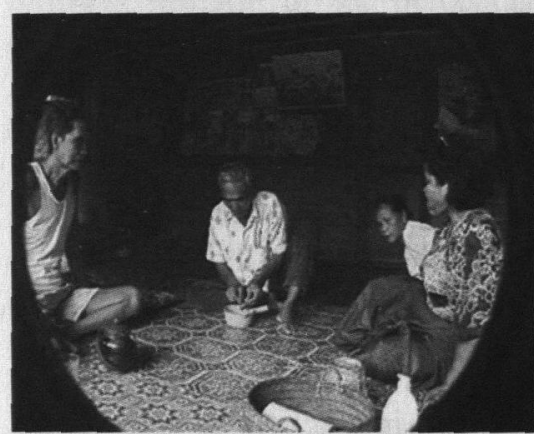

Figure $3 a$.

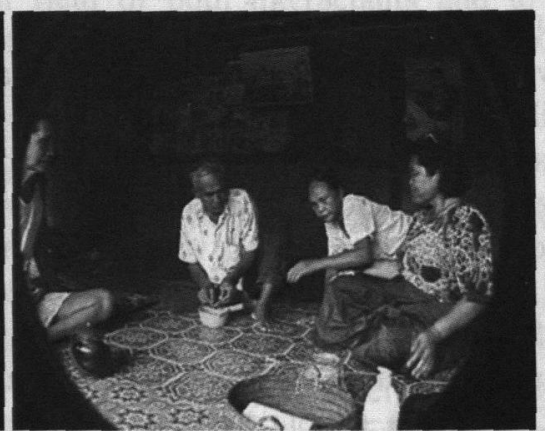

Figure $3 b$.

BW's forward-reaching action gives rise to an inference by FW that BW wants the basket. ${ }^{3}$ We can tell FW has made this inference from the fact that she grasps the basket and passes it to BW in Fig. 4. And we can tell, in 
addition, from what she says next, in line 1 of (1), that she infers BW wants to chew betel nut (the numbers at the end of each Lao word mark lexical tone distinctions):
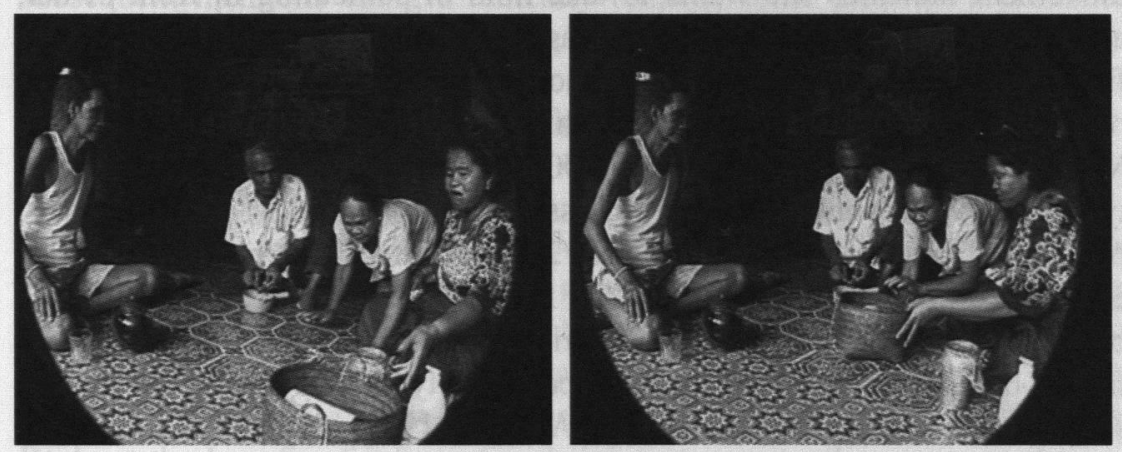

Figure $4 a$.

Figure $4 b$.

(1) $1 \mathrm{FW}$ caw4 khiaw4 vaa3

2SG.P chew QPLR.INFER

$2 \mathrm{BW} \quad \mathrm{mm} 5$

INTJ

Mm. (i.e. Yep.)

FW infers more than one thing from the forward-reaching action of BW shown in Fig. 3. It would seem hardly culture specific that BW is taken to want the basket. (But an inference or projection is nevertheless being made; after all, she may have wanted to rub a spot of dirt off the floor where the basket was sitting.) More specific to the common ground that comes with this cultural setting, BW's reaching for the basket is basis for an inference that she wants to chew betel nut (and not, for instance, that she wants to reorganize the contents of the basket, or tip it out, or put it away, or spit into it). The inference that BW wants to chew betel nut is made explicit in the proposition in line 1 "you chew." The added sentence-final "evidential interrogative" particle vaa3 (Enfield 2007b:45) makes explicit, in addition, that it is an inference. The particle vaa 3 encodes the notion that an inference has been made, and seeks confirmation that this inference is correct: that is, in a sequence $X v a a 3$, the meaning of vaa 3 can be paraphrased along the lines "Something makes me think $\mathrm{X}$ is the case, you 


\section{Nicholas J. Enfield}

should say something now to confirm this." BW responds appropriately with a minimal spoken confirmation in line 2 .

The two inferences made in this example--one, that BW's forward movement indicates she wants to take hold of something in front of her, and two, that she wants to have the basket to chew betel nut--are launched from different types of categorical knowledge (though they are both based on the attribution of intention through recognition of an agent's "attitude"; Mead 1934, see also Kockelman 2005). The first is a general stock of typifications determined naturally, essentially by biology: naive physics, parsing of motor abilities (Byrne 2006), frames of interpretation of experience arising through terrestrial fate (Levinson 1997: 28). A second basis for inference is the set of categories learned in culture--here, from the fate of being born in a Lao-speaking community, and acquiring the frames, scripts, and scenarios (Schank and Abelson 1977) of betel-nut chewing among older ladies in rural Laos (e.g., that betel paraphernalia is "free goods" that any middle-aged or older woman may reach for in such a setting-had a man or a child made the same reaching action here, they would not have been taken to be embarking on a betel-chewing session). Both these types of knowledge are in the common ground of these interlocutors, in the strict sense of being information openly shared.

\section{Grounding for inferring: The informationally strategic pursuit of common ground}

Links between joint attention, common ground, and pragmatic inference suggest a process of grounding for inferring, by which the requirements of human sociality direct us to tend-while socializing-to dimensions of common ground that may be exploited in later socializing. ${ }^{4}$ This formulation highlights the temporality of the connection between grounding (i.e., securing common ground) and inferring. Grounding is an online process (enabled by joint attention). Later inferring based on common ground presupposes or indexes the earlier establishment of that common ground (or indexes a presumption of that common ground, based on some cue, such as a person's individual identity, or some badge of cultural or subcultural identity).

Grounding for inferring takes place at different levels of temporal grain - that is, with different time lags between the point of grounding and the point of drawing some inference based on that grounding. At a very 
local level, it is observable in the structure of reference management through discourse (Fox 1987). Canonically, a referent's first mention is done with a full noun phrase (e.g., a name or a descriptive reference), with subsequent mentions using a radically reduced form (such as a pronoun; recorded example from Fox 1987:20, transcription simplified):

(2) A: Did they get rid of Kuhleznik yet?

B: No in fact I know somebody who has her now.

Forms like her do not identify or describe their referent. Their reference must be retrieved by inference or other indexical means. This is straightforward when a full form for the antecedent is immediately prior, as in (2). But if you miss the initial reference, lacking the common ground required for inferring what her must be referring to, you might be lost. Without the benefit of informative hand gestures or other contextual cues, you are likely to have to disrupt the flow of talk by asking for grounding, to be able to make the required referential inferences.

At a step up in temporal distance between grounding and payoff are forward-looking "setups" in conversational interaction (Jefferson 1978; Sacks 1974; cf. Goodwin's "prospective indexicals"; Goodwin 1996: 384), which, for instance, alert listeners to the direction in which a speaker's narrative is heading. When I say "Her brother is so strange, let me tell you what he did last week," you as listener will then need to monitor my narrative for something that is sufficiently strange to count as the promised key illustration of her brother's strangeness, and thus the punch line. What constitutes "her brother's strangeness" is "not yet available to recipients but is instead something that has to be discovered subsequently as the interaction proceeds" (Goodwin 1996:384). When you hear what you think is this punch line, you will likely surmise that the story is at completion. Your response will be shaped by a second function of the prospective expression, namely, as a forewarning of the appropriate type of appraisal that the story seeks as a response or receipt. So, "He's so strange, let me tell you..." will rightly later elicit an appreciation that is fitted to the projected assessment; for example, Wow, how weird. Setup expressions of this kind are one type of grounding for inferring, with both structural-informational functions (putting in the open the fact that the speaker is engaged in a sustained and directed activity of telling - e.g., "how strange her brother is"), and social-affiliational functions (putting in the open the speaker's stance toward the narrated situation, which facilitates the production of affiliative, or at least fitted response). Both these functions help constrain a 


\section{Nicholas J. Enfield}

listener's subsequent interpretation as appropriate to the interaction, at a discourse level.

All the way at the other end of the scale in temporal distance between grounding and its payoff are those acts of building common ground that look ahead into the interactional future of the people involved. At a personal level, our efforts to maintain and build common ground have significant consequences for the type of relationship we succeed in ongoingly maintaining, that is, whether we are socially close or distant (see below). At a cultural level, in children's socialization we spend a lot of time explaining and acting out for children "what people do," "what people say," and "how things are." This builds the cultural common ground that will soon streamline an individual's passage through the moment-by-moment course of their social life.

\section{Semiotics: Cognition and perception, structure, and emergence}

A matter of some contention is the degree of involvement of higher-order cognition in these social interactional processes. Despite currency of the term "mind reading" and its variants in literature on social intelligence (Baron-Cohen 1995; Carruthers and Smith 1996; Astington 2006), we cannot read each other's minds. Miller wrote, "One of the psychologist's great methodological difficulties is how he can make the events he wishes to study publicly observable, countable, measurable" (1951: 3). This problem for the psychologist is a problem for the layperson too. In interaction, normal people need, at some level, to be able to model each other's (evolving and contingent) goals, based solely on perceptible information, by attending to one another's communicative actions and displays (Mead 1934). A no-telepathy assumption means that there is "no influencing other minds without mediating artifactual structure" (Hutchins and Hazlehurst 1995). As a result, semiosis - the interplay of perception and cognition, rooted in ethology and blossoming in the modern human mind--is a cornerstone of human sociality (Kockelman 2005; Peirce 1965). Humans augment the ethologically broad base of iconic and indexical meaning with symbolic structures and higher-order processes of intention attribution.

So if action and perception are the glue in human interaction, higherorder cognition is the catalyst. I see this stance as a complement, not an alternative, to radically interactionist views of cognition (cf. Molder and 
Potter 2005). Authors like Norman (1991), Hutchins (1995), and Goodwin $(1994,1996)$ are right to insist that the natural exercising of cognition is in distributed interaction with external artifacts. And we must add to these artifacts our bodies (Enfield 2005; Goodwin 2000; Hutchins and Palen 1993) and our social associates (Goodwin 2006). Similarly, the temporallogical structures of our social interactions are necessarily collaborative in their achievement (Clark 1996; Schegloff 1982), as may be our very thought processes (Goody 1995; Mead 1934, Rogoff 1994; Vygotsky 1962). But as individuals, we each physically embody and transport with us the wherewithal to move from scene to scene and still make the right contributions. We store cognitive representations (whether propositional or embodied) of the conventional signs and structures of language, of the cultural stock of conventional typifications that allow us to recognize what is happening in our social world (Schutz 1970), and of more specific knowledge associated with our personal contacts. And we have the cognitive capacity to model other participants' states of mind as given interactions unfold (Mead 1934).

Accordingly, here is my rephrasing of Miller (with a debt to Schutz 1970 and Sacks 1992): One of the man in the street's great methodological difficulties is how he can understand (and make himself understood to) his social associates solely on the basis of what is publicly observable. Any model of multiparty interaction will have to show how the combination of a physical environment and a set of mobile agents will result in emergence of the structures of interactional organization that we observe. It will also have to include descriptions of the individual agents, their internal structure and local goals. General capacities of social intelligence, and specific values of common ground will have to be represented somewhere in those individual minds. Then, in real contexts, what is emergent can emerge.

So, human social interaction not only involves cognition, it involves high-grade social intelligence (Goody 1995; allowing that it need not always involve it-Barr and Keysar 2004). And in line with those who resist the overuse or even abuse of mentalistic talk in the analysis of social interaction, it is clear that intention attribution is entirely dependent on perception in a shared environment (see esp. Byrne 2006; Danziger 2006; Goodwin 2000, 2006; Hutchins 1995:ch. 9, 2006; Schegloff 1982:73). Both components-individual cognition and emergent organization-are absolutely necessary (see Enfield and Levinson 2006). Human social interaction would not exist as we know it without the cocktail of individual, higherorder cognition and situated, emergent, distributed organization. A 


\section{Nicholas J. Enfield}

mentalist stance need therefore not be at the expense of the critically important emergence of organization from collaborative action in shared physical context, above and beyond any individual's internally coded goals. To be sure, there remain major questions as to the relative contribution of individual cognition and situated collaborative action in causing the observed organization of interaction. But however you look at it, we need both.

\section{Audience design}

Equipped with higher-order inferential cognition, an interlocutor (plus all the other aspects of one's interactional context), and a stock of common ground, a speaker should design his or her utterances for that interlocutor (Clark 1996; Sacks 1992; Sacks and Schegloff 1979; Schegloff 1997; Enfield and Stivers 2007; Kitzinger and Lerner 2007). If we are to optimize the possibility of having our communicative intentions correctly recognized, any attempt to make the right inferences obvious to a hearer will have to take into account the common ground defined by the current speaker-hearer combination. In ordinary conversation, there is no generic, addressee-general, mode of message formulation. To get our communicative intentions recognized, we ought to do what we can to make them the most salient solutions to the interpretive problems we foist on our hearers. The right ways to achieve this will be determined in large part by what is in the common ground, and this is by definition a function of who is being addressed given who it is they are being addressed by. Because Gricean implicature is fundamentally audience driven (whereby formulation of an utterance is tailored by how one expects an addressee will receive it), to do audience design is to operate at a yet higher level than mere intention attribution. It entails advance modeling of another's intention attribution. ${ }^{5}$

Consider an example that turns on highly local common ground. Fig. 5 shows two men sitting inside a Lao village house, waiting while lunch is prepared in an outside kitchen. 


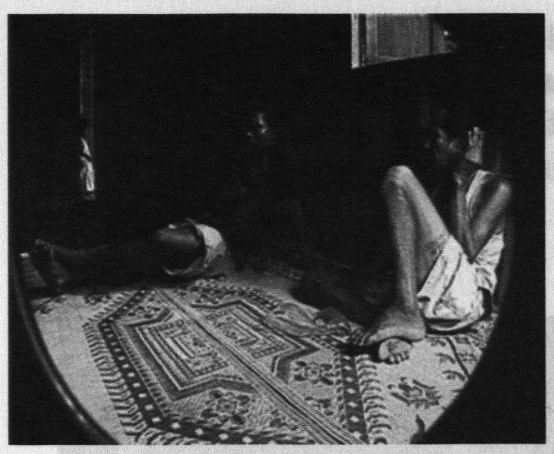

Figure 5.

At the moment shown in Figure 5, a woman's voice can be heard (coming from the outside kitchen verandah, behind the camera, left of screen) as follows:

(3) mòòt4 nam4 haj5 nè̀1
extinguish water give IMP.SOFT
Please turn off the water for (me).

In making this request, the speaker does not explicitly select an addressee. Anyone in earshot is a potential addressee. Within a second or two, the man on the left of frame gets up and walks to an inside wall of the house, where he flicks an electric switch.

Consider the mechanism by which the utterance in (3) brought about this man's compliance. Although the woman's call in (3) was not explicitly addressed to a particular individual, it was at the very least for someone who was in hearing range and knew what compliance with the request in (3) entailed. Although relative social rank of hearers may work to narrow down who is to carry out the request, it remains that the utterance in (3) could not be intended for someone who lacks the common ground, that is, who does not know what "turning off the water" involves. The switch that controls an outside water pump is situated at the only power outlet in the house, inside, far from the kitchen verandah. To respond appropriately to the utterance in (3), an addressee would need this inside knowledge of what "turning off the water" entails. Without it, one might not even realize that the addressee of (3) is someone (anyone) inside the house. But it is in the common ground for the people involved in this exchange. They are neighbors of this household, daily visitors to the house. The woman outside 


\section{Nicholas J. Enfield}

on the verandah knows that the people inside the house know (and know that they are known to know!) the routine of flicking that inside switch to turn the outside water pump on and off. This enables the success of the very lean communicative exchange consisting of the spoken utterance in (3) and the response in Fig. 6.

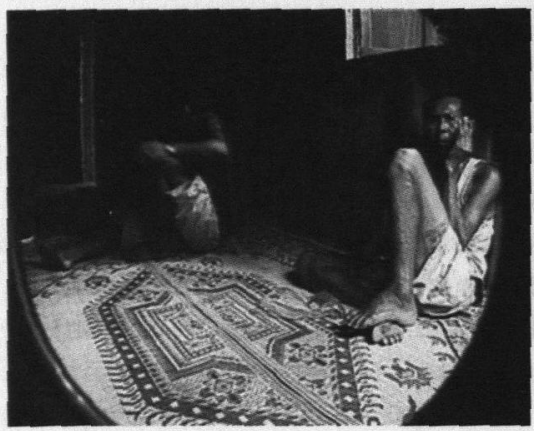

Figure $6 a$.

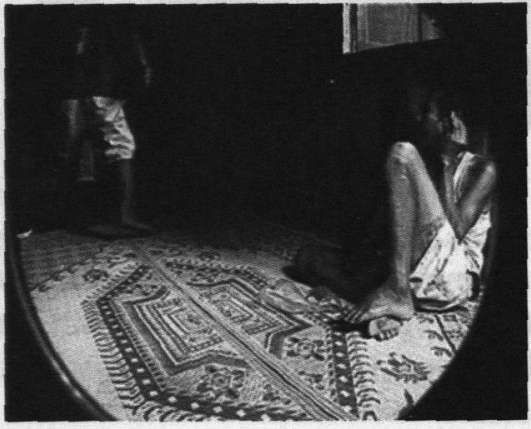

Figure $6 b$.

Much is inferred by the actor in Fig. 6 beyond what is encoded in the spoken message in (3), in the amplicative sense outlined above. In addition, this example illustrates a defining feature of common ground information, namely that people cannot deny possessing it. ${ }^{6}$ The man on our left in Fig. 5-who is situated nearest the switch-might not feel like getting up, but he could not use as an excuse for inaction a claim that he does not know what the speaker in (3) wants (despite the fact that nothing in her utterance makes this explicit).

The principle of audience design dovetails with common ground, because both are defined by a social relationship between interlocutors. As prefigured above, the general imperative of audience design is served by two, more specific imperatives of conversation. I described one of thesethe informational imperative-as the cooperative struggle to maintain common referential understanding, mutually calibrated at each step of an interaction's trajectory (Clark 1996; Schegloff 1992). This will be satisfied by various means including choice of language spoken, choice of words, grammatical constructions, gestures, and the various devices for meeting "system requirements" for online alignment in interaction (mechanisms for turn organization, signals of ongoing recipiency, correction of errors and other problems, etc.; Goffman 1981:14; Schegloff 2006). Less well 
understood are the "ritual" requirements of remedial face work, and the need to deal with "implications regarding the character of the actor and his evaluation of his listeners, as well as reflecting on the relationships between him and them" (Goffman 1981:21; cf. Goffman 1967, 1971). We turn now to those.

\section{The affiliational imperative in social interaction}

Any time one is engaged in social interaction, one's actions are of real consequence to the social relationship currently being exercised. If you are acting too distant, or too intimate, you are most likely going to be held accountable for it. Heritage and Atkinson (1984:6) write that there is "no escape or time out" from the considerations of interaction's sequential, contextual nature. Similarly, there is no escape or time out from the socialrelational consequences of interaction. Just as each little choice we make in communicative interaction can be assessed for its optimality for information exchange, it can equally be assessed for its optimality for maintaining (or forging) the current social relationship at an appropriate level of intensity or intimacy. The management of common ground is directly implicated in our perpetual attendance to managing personal relationships within our social networks. Next, I elaborate some mechanisms by which this is achieved, but first I want to flesh out what is meant by degrees of intimacy or intensity in social relationships.

One of the key tasks of navigating social life is maintaining positions in social networks, where relationships between individuals are carried through time, often for years. There are logical constraints on the nature of an individual's network of relationships thanks to an inverse relationship between time spent interacting with any individual, and number of individuals with whom one interacts. We have only so much time in the day, and sustained relationships cannot be multiplied beyond a certain threshold (cf. grooming among primates; Dunbar 1993, 1996). Spending more time interacting with certain individuals means more opportunities to increment common ground with those individuals, by virtue of the greater opportunity to engage in joint attentional activity such as conversation. This results in greater access to amplicative inference in communication. A corollary is having less time to interact with others, and thus less chance to increment common ground through personal contact with those others, and, 


\section{Nicholas J. Enfield}

in turn, less potential to exploit ampliative inference in communication with them.

Such considerations of the logical dynamics of time and social group size have been taken to suggest inherent biases in the organization of social network structure (Dunbar 1998; Dunbar and Spoors 1995; Hill and Dunbar 2003). Hill and Dunbar suggest that social networks are "hierarchically differentiated, with larger numbers of progressively less intense relationships maintained at higher levels" (2003: 67; cf. Dunbar 1998). They propose a model with inclusive levels (Hill and Dunbar 2003: 68; note that they also discuss groupings at higher levels than this)

\begin{tabular}{ll}
\hline (4) Level of relationship intensity & Approximate size of group \\
\hline support clique & 7 \\
sympathy group & 21 \\
band & 35 \\
social group & 150 \\
\hline
\end{tabular}

What defines membership in one or other of these levels? As with physical grooming among primates, those who I spend more time with in committed engagement will tend to be those who I can later rely on in times of trouble (and, similarly, to whom I will be obliged to offer help if needed). In some societies this will be somewhat preordained (e.g., by kin or equivalently fixed social relations), whereas in other types of societies people may be more freely selective (as in many modern urban settings). For humans, unlike in primitive physical grooming, such rounds of engagement are intertwined with the deployment of delicate and sophisticated symbolic structure (language), and so it is not (just?) a matter of how long we spend interacting with whom, but of what kind of information is traded and thereby invested in common ground. This is why in one type of society I might have a more intensive, closer relationship with my best friend, even though I see very much less of him than my day-to-day professional colleagues.

Cultures will differ with respect to the determination of relationship intensity (quantitatively and qualitatively defined), and the practices by which such intensity is maintained and signaled. Hill and Dunbar suggest that a hierarchical structure of social relatedness like (4), above, will be maintained in more or less any cultural setting, but the qualitative basis for distinction between these levels in any given culture will be "wholly open to negotiation" (i.e., by the traditions of that culture; 2003:69). They cite various types of social practice that may locally define the relevant level of 
relationship: those from whom we get our hair care (among the !Kung San; Sugawara 1984), those "whose death would be personally devastating" (Buys and Larson 1979), those "from whom one would seek advice, support, or help in times of severe emotional or financial stress" (Dunbar and Spoors 1995), those to whom we would send Christmas cards (Hill and Dunbar 2003; the other citations in this sentence are also from Hill and Dunbar 2003: 67). An important empirical project is the investigation of commonality and difference in how people of different cultures mark these social distinctions through interactional practice (regardless of whether membership in different levels of relationship intensity in a given setting is socioculturally predetermined or selected by individuals' preference).

Practices concerned with the management of common ground for strategic interactional purposes provide, I suggest, an important kind of data for assessing Hill and Dunbar's proposal. Given the "no time out" nature of everyday interaction, we may better look to practices that are very much more mundane and constant in the lives of regularly interacting individuals than, say, annual gestures like the Anglo Christmas Card. To this end, I want to draw a key link, so far entirely unseen in the literature, it seems, between the line of thinking exemplified by Hill and Dunbar (2003), and a strand of work arising from research within corners of sociology on conversation and other types of interaction, rooted in the work of Sacks and associates on "social membership categorization" (cf. Sacks 1992; see also Garfinkel and Sacks 1970; Schegloff 2002). In a review of this work, Pomerantz and Mandelbaum (2005) outline four types of practice in U.S. English conversation by which people "maintain incumbency in complementary relationship categories, such as friend-friend, intimateintimate, father-son, by engaging in conduct regarded as appropriate for incumbents of the relationship category and by ratifying appropriate conduct when performed by the cointeractant" (Pomerantz and Mandelbaum 2005:160):

(5) Four sets of practices for maintaining incumbency in more intensive/intimate types of social relationships (derived from Pomerantz and Mandelbaum 2005):

- "Inquiring about tracked events and providing more details on one's own activities": reporting and updating on events and activities mentioned in previous conversations; eliciting detailed accounts, demonstrating special interest in the details; attending to each other's 


\section{Nicholas J. Enfield}

schedules and plans; and so forth (Drew and Chilton 2000; Morrison 1997).

- "Discussing one's own problems and displaying interest in the other's problems": claiming the right to (and being obliged to) ask and display interest in each other's personal problems; showing receptivity to such discussion; and so forth (Cohen 1999; Jefferson and Lee 1980).

- "Making oblique references to shared experiences and forwarding the talk about shared experiences": one party makes minimal reference to past shared experience (e.g., John says Remember Mary's brother?), and the other displays their recognition of it, takes it up and forwards it in the conversation (Fred responds Oh God, he's so strange, what about when he...), thereby demonstrating the common ground. (Lerner 1992; Mandelbaum 1987; Maynard and Zimmerman 1984; cf. Enfield 2003)

- "Using improprieties and taking up the other's improprieties by using additional improprieties and/or laughter": cussing and other obscenities; laughter in response to such improprieties; shared suspension of constraints usually suppressed by politeness (Jefferson 1974).

At least the first three of these cases are squarely concerned with the strategic manipulation of information-the incrementing, maintaining, or presupposing of common ground - with consequences for the relationship and for its maintenance. These are important candidates for local, culturally variant practices for maintaining social membership in one or another level (the examples in [5] being all definitive of "closer" relationships). Whether these are universal is an empirical question. It requires close analysis of social interaction based on naturally occurring, informal conversation across cultures and in different types of socialcultural systems.

I now want to elaborate with further examples of social practices from specific cultural settings that show particular attention to the maintenance of social relationships at various levels. In line with the theme of the chapter, they concentrate on the management of, or presupposition of, common ground, with both informational payoffs and social-affiliational payoffs.

A first example, from Schegloff (2007), is a practice that arises in the cultural context of Anglo-American telephone calls (at least before the era of caller ID displays). It hinges on the presumption that people in close 
social relationships should be able to recognize each other by a minimal voice sample alone. Here is an example:

(6) $1 \quad$ ((ring))

2 Clara: Hello

3 Agnes: $\mathrm{Hi}$

4 Clara: Oh hi, how are you Agnes

This typical case displays an exquisite minimality and efficiency, which puts on mutual display to the interlocutors the intimacy of their relationship, thanks to the mutual presumption of person recognition based on minimal information. In line 1, Clara hears the phone ring. When she picks up, in line 2, she does not identify herself by saying who she is. She gives a voice sample carried by the generic formula "hello." If the caller is socially close enough to the callee, he or she will recognize her by her voice (biased by expectation, given that one usually knows who one is calling). On hearing this, Schegloff explains, by supplying the minimal greeting response "Hi" in line 3 , the caller "claims to have recognized the answerer as the person they meant to reach." (Otherwise-i.e., if the caller did not recognize the answerer-he or she would have to ask, or at least ask for confirmation; e.g., "Clara?") At the same time, the caller in line 3 is reversing the direction of this minimal-identifying mechanism, providing "a voice sample to the answerer from which callers, in effect, propose and require that the answerer recognize them." In this seamless and lightningfast exchange, these interactants challenge each to recognize the other given the barest minimum of information, and through the course of the exchange each of them claim to have achieved that recognition. (Clara not only claims but demonstrates recognition by producing Agnes's name in line 4.) Were they not to recognize who was calling on the basis of a small sample of speech like "hi"- - which, after all, was produced on the presumption that the quality of the voice should be sufficient for a close social associate to identify the person-they would pay a social price of disaffiliation via a betrayal of distance and lack of intimacy ("What? You don't recognize me?!;" cf. Schegloff 2007).

Consider a second example, another practice by which social interactants identify persons. In English, when referring to a nonpresent person in an informal conversation, a speaker may choose whether to use bare first name (John) as opposed to some fuller name (John Smith) or description (my attorney, Bill's brother, that guy there; Sacks and Schegloff [1979]2007, Enfield and Stivers 2007). The choice depends on whether it is 


\section{Nicholas J. Enfield}

in speaker and addressee's common ground who "John" is and whether he is openly known to this speaker-addressee pair as John. The choices we make will, in general, reflect the level of intimacy and intensity of social relations among speaker, addressee, and referent, and this more directly concerns the common ground of speaker and addressee. In my example (Fig. 7), Kou (left) has just arrived at his village home, having been driven from the city ( 30 or so $\mathrm{km}$ away) in a pickup. He has brought with him a load of passengers, mostly children, who have now scattered and are playing in the grounds of his compound. Saj (right), a neighbor of Kou, has just arrived on the scene.

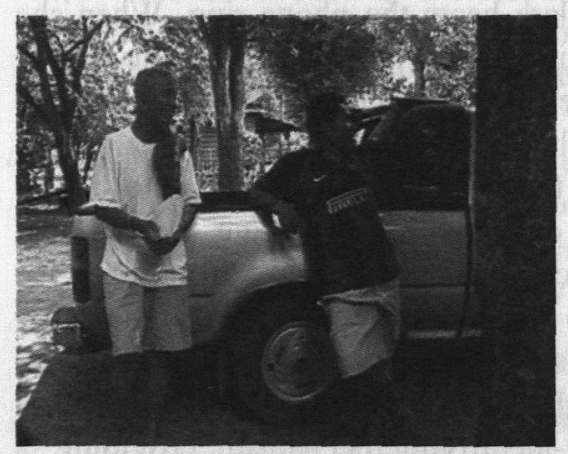

Figure 7.

Saj asks Kou how many people were in the group that has just arrived with Kou's vehicle, following this up immediately by offering a candidate set of people: "Duang's lot" (line 1). The named referent-Duang-is Kou's third daughter. ${ }^{8}$ Kou responds with a list of those who have arrived with him, beginning by listing four of his own daughters by name (lines 2-3), then mentioning two further children (line 4):

(7)

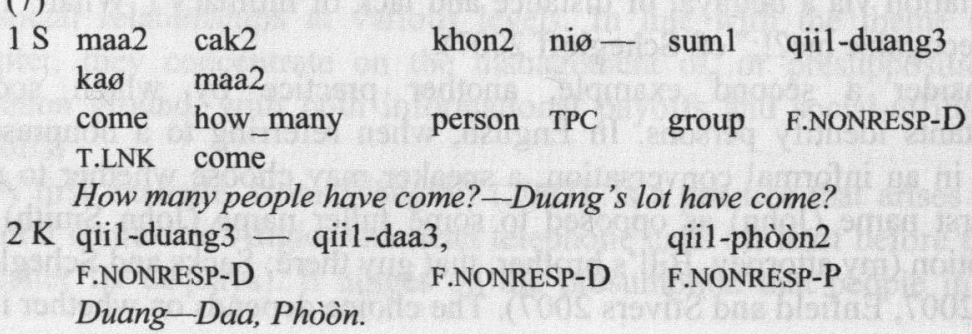


3 maa2 bet2 lèq5, qiil-khòòn2van3

come all PRF F.NONRESP-K

All have come, Khòònan.

4 dêk2-nòòj4 maa 2 tèè 1 paak 5 san 2 phunø qiik5 sòòng3

khon2

child-small come from $P$ DEM.FAR more two

person

Kids from Paksan, another two.

It is in the common ground that Kou's own four children are known to both Kou and Saj by their first names. Kou is therefore able to use the four children's personal names in lines 2-3 to achieve recognition. In line 4, Kou continues his list, with two further children who have arrived with him. These two are not his own, are not from this village, and are presumed not to be known by name to Saj. They are children of Kou's brother and sister, respectively, who both live in Kou's mother's village Paksan, some distance away. Kou refers to them as "kids from Paksan." The reason he does not he refer to these two children by name is that he figures his addressee will not recognize them by name-their names, as ways of uniquely referring to them, are not in the common ground. But although Saj certainly will not recognize the children by name, he will recognize their village of origin by name (and further, will recognize that village to be Kou's village of origin, and the home of Kou's siblings). So Kou's solution to the problem of formulating reference to these two children-in line 4 -is to tie them to one sure piece of common ground: the name of the village where a host of Kou's relatives are (openly, mutually) known to live.

However, it appears that Kou's solution in line 4 is taken-by Saj-to suppose too little common ground. Although Saj would not know the names of these Paksan children, he does know the names of some of Kou's siblings from Paksan. This is common knowledge, which could form the basis of a finer characterization of these children's identities than that offered in line 4 . What immediately follows Kou's vague reference to the two children by place of origin in line 4 is Saj's candidate offer of a more specific reference to the children. Saj's candidate reformulation (line 5 in [8], below) links the children explicitly to one of Kou's siblings, referring to him by name. This guess, which turns out to be not entirely correct, succeeds in eliciting from Kou a finer characterization of the children's identities (line 6). This new characterization presupposes greater common ground than Kou's first attempt did in line 4, yet it remains a step away in 
implied social proximity from that implied by Kou's first-name formulations to his own children in lines $2-3$, above:

(8) (Follows directly from (7))

$5 \quad \mathrm{~S} \quad$ luuk4 qajø-saaj3

child eBr-S

Children of Saaj?

$6 \mathrm{~K}$ luuk4 bak2-saaj3phuu5 nùng1, luuk4-qiil-vaat4sanaa3

phuu5 nùng1

child F.NONRESP-S person one child F.NONRESP-V

person one

Child of Saaj, one, child of-Vatsana, one.

The contrasts between the three ways to formulate reference to a person-by first name in lines 1-3, via place of origin in line 4, via parent's name in lines 5-6-represent appeals to common ground of different kinds, and different degrees. They are indicative of, and constitutive of, different levels of social familiarity and proximity. This example shows how such expression of these levels of familiarity can be explicitly negotiated within the very business of social interaction. Kou's reference to the two children from Paksan in line 4 was constructed differently to the references to his own children in lines $2-3$, but Saj effectively requested, and elicited, a revision of the first-attempt formulation in line 5, thereby securing a display of greater common ground than had a moment before been presupposed. $^{9}$

A third example involves two men in a somewhat more distant relationship. This is from an exchange between the two men pictured on the left of Figs. 2-4, above. (I call them Foreground Man [FM] and Background Man [BM].) The men hardly know each other, but are of a similar age. The younger sister of BM's younger brother's wife is married to the son of FM. The two men seldom meet. Their kinship ties are distant. Their home territories-the areas about which they should naturally be expected to have good knowledge--overlap partially. They originate in villages that are a day's travel apart. This is far enough to make it likely that they have spent little time in each other's territory, but it is not so far that they would be expected to not have ever done so. The common ground at stake, then, concerns knowledge of the land.

The conversation takes place in the village of FM. This is therefore an occasion in which BM is gathering firsthand experience beyond his home territory. It may be inferred from the segment we are about to examine that 
FM wants to display his familiarity with BM's territory. The point of interest in this conversation is a series of references to a geographical location close to BM's home village, but which FM apparently knows well about. Although the men are discussing medicinal herbs, BM mentions an area in which certain herbs can be found. His first mention of the place is by name: Vang Phêêng. ${ }^{10}$ As with reference to persons (see previous example), the use of the bare name in first mention presupposes recognizability or identifiability (Schegloff 1972). This identifiability is immediately confirmed by FM's reply of "Yeah, there's no shortage (of that herb) there." There is then over a minute's further discussion of the medicine, before the following sequence begins: ${ }^{11}$

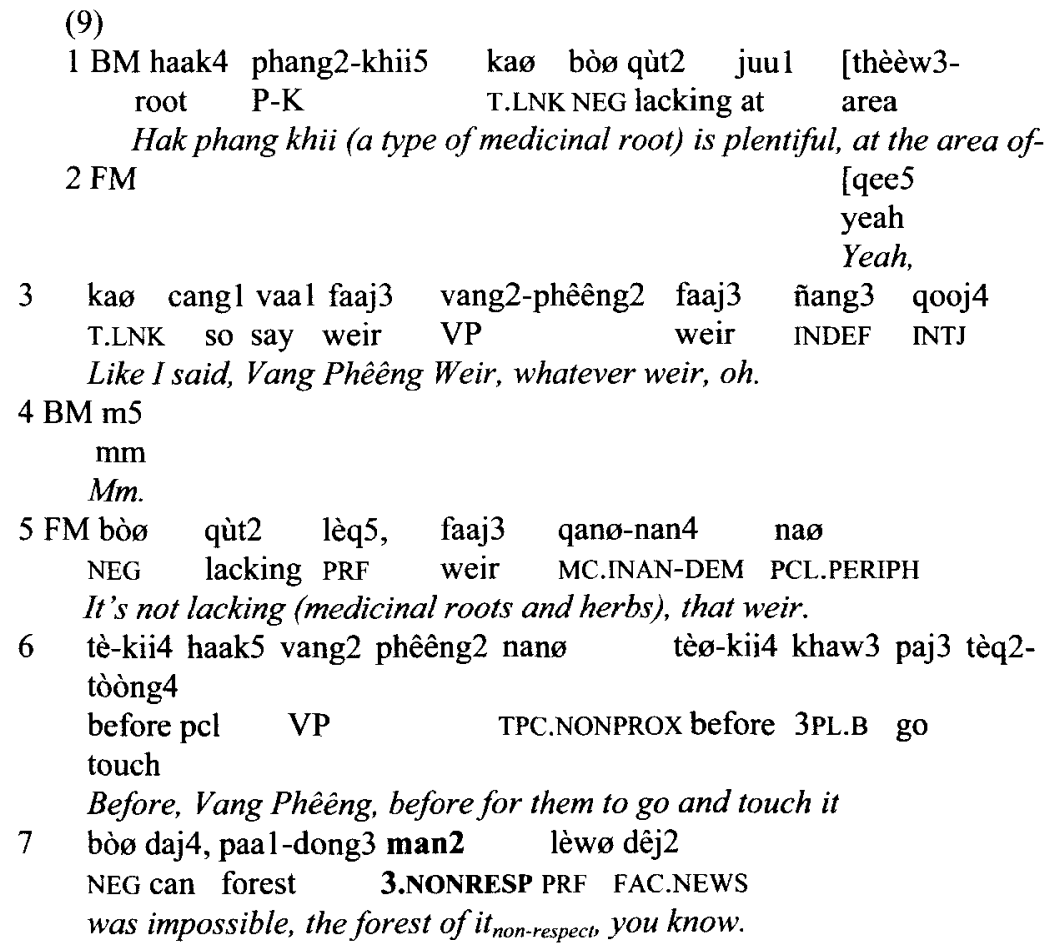

In line 1, BM mentions a type of herbal medicine, saying that it is plentiful. He is about to mention the location in which it is plentiful, as projected by the use of the locational marker glossed in line 1 as "at." Not only does FM anticipate this, but also anticipates which location it is that BM is about to mention (in a form of anticipation directly related to that in the more simple 


\section{Nicholas J. Enfield}

example shown above in Figs. 2-4), namely Vang Phêêng Weir (line 3). (cf. Lerner 1996 on collaborative turn completion.) This is confirmed by BM's acknowledgement marker "mm" in line 4. Again, we see a dance of display of common ground, by anticipation of what the current speaker is going to say. FM goes on to comment in lines 6-7 that in the old days it was impossible to collect medicinal herbs from the area.

The element of special interest here is the pronoun man2 "it" in bold face in line 7. There is no local antecedent for this pronoun. The speaker is using a locally subsequent form in a locally initial position (Fox 1987; Schegloff 1996), with a subsequent major risk of not succeeding in getting recognition. How do his addressees know what he is talking about? (We get evidence that BM at least claims to follow him, as we see BM in the video doing an acknowledging "head toss"--something like a nod--directed to FM just as the latter utters line 7.) A couple of lines ensue (omitted here to save space), which finish with FM repeating that in the old days it was impossible to get medicinal herbs out of there. Then, FW contributes:

(10)

$$
\begin{aligned}
& 8 \mathrm{FW} \text { khuam2 phen1 haaj4 niø naø } \\
& \text { reason } 3 . P \text { angry TPC TPC.PERIPH } \\
& \text { Owing to it's respect being angry? } \\
& 9 \text { FM qee5 - bòò1 mèèn2 lin5 lin5 dêj2, phii3 vang2 phêêng2 niø } \\
& \text { yeah NEG be play play FAC.NEWS spirit V PCL } \\
& \text { Yeah-It's not playing around you know, the spirit of Vang Phêeng. }
\end{aligned}
$$

Line 8, uttered by FW (BM's wife) partly reveals her analysis of what FM is saying, and specifically of what he was referring to by the $3 \mathrm{rd}$ person singular pronoun man 2 in Line 7 . She, too, uses a 3rd-person singular pronoun, but her choice is the polite phenl. She suggests that the previous difficulties in extracting herbs is because of "the anger of it." Someone who lacks the relevant cultural common ground will have no way of knowing that the referent of "it" is the spirit owner of Vang Phêêng. This is not made explicit until it seems obvious that everyone already knows what the speaker has been talking about--that is, as a demonstrative afterthought in line 9.

This exchange reveals to the analyst the extent to which recognition of quite specific references can be elicited using very minimal forms for reference when those involved in the social interaction share a good deal of common ground (cf. [3] and Figs. 5-6, above). It also makes important indications to the participants themselves. They display to each other, in a 
way hardly possible to fake, that they share specific common ground. In line 3 of (9), FM anticipates what BM is going to say, and says it for him. In line 7, FM uses a nearly contentless pronoun to refer to a new entity in the discourse, relying entirely on shared knowledge and expectation to achieve successful recognition. ${ }^{12}$ In line $8, \mathrm{FW}$ displays her successful recognition of the referent introduced by FM in line 7, by making explicit something about the referent that up to this point has been merely implied. By the economy and brevity of these exchanges, these individuals display to each other-and to us as onlookers-that they share a great deal of common knowledge, including common knowledge of the local area (and the local biographical commitment this indexes), and membership in the local culture. This may be of immense value for negotiating the vaguely defined level of interpersonal relationship pertaining between the two men, whose only reason for interacting is their affinal kinship. In conversing, they test for, and display common ground, and through the interplay of their contributions to the progressing trajectory of talk demonstrate a hardto-fake ability to know what is being talked about before it is even mentioned.

\section{Conclusion}

This chapter has proposed that the practices by which we manage and exploit common ground in interaction demonstrate a personal commitment to particular relationships and particular communities, and a studied attention to the practical and strategic requirements of human sociality. I have argued that the manipulation of common ground serves both interactional efficacy and social affiliation. The logic can be summarized as follows. Common ground-knowledge openly shared by specified pairs, trios, and so forth-is by definition socially relational, and relationship defining. In an informational dimension, common ground guides the design of signals by particular speakers for particular recipients, as well as the proper interpretation by particular recipients of signals from particular speakers. Richer common ground means greater communicative economy, because it enables greater ampliative inferences on the basis of leaner coded signals. In a social-affiliational dimension, the resulting streamlined, elliptical interaction has a property that is recognized and exploited in the ground-level management of social relations: these indices of common ground are a means of publicly displaying, to interactants and onlookers 


\section{Nicholas $J$. Enfield}

alike, that the requisite common ground is indeed shared, and that the relationship constituted by that degree or kind of common ground is in evidence.

In sum, common ground is as much a social-affiliational resource as it is an informational one. In its home disciplines of linguistics and psychology, the defining properties of common ground concern its consequences in the realm of reference and discourse coherence. But sharedness, or not, of information, is essentially social. Why else would it be that if I were to get the promotion, I had better tell my wife as soon as I see her (or better, call her and let her be the first to know), whereas others can be told in due course (my snooker buddies), and yet others need never know (my dentist)? The critical point, axiomatic in research on talk in interaction yet alien to linguistics and cognitive science, is that there is no time out from the social consequences of communicative action.

\section{Acknowledgements}

This chapter was previously published in 2006 in the volume Roots of human sociality (Oxford: Berg, edited by NJ Enfield and SC Levinson), with the title 'Social Consequences of Common Ground'. The present version includes minor revisions. I thank Berg Press for granting permission to reproduce the chapter in this volume. I would like to acknowledge a special debt to Bill Hanks, Steve Levinson, Paul Kockelman, Tanya Stivers, Herb Clark, Chuck Goodwin, John Heritage, and Manny Schegloff, along with the rest of my colleagues in the Multimodal Interaction Project (MPI Nijmegen)—Penny Brown, Federico Rossano, JP de Ruiter, and Gunter Senft-for helping me develop my thinking on the topics raised here. I received helpful commentary on draft versions from Steve Levinson, Tanya Stivers, as well as Jack Sidnell and two other anonymous reviewers. None are responsible for errors and infelicities. I gratefully acknowledge the support of the Max Planck Society. I also thank Michel Lorrillard for providing me with a place to work at the Vientiane centre of l'École française d'Extrême-Orient, where final revisions to this chapter were made. Finally, I thank the entire cast of contributors to the Roots of Human Sociality symposium at the village of Duck, on North Carolina's Outer Banks, October 2004. Lao transcription and abbreviations follow Enfield (2007b). 


\section{Notes}

1. See also Schiffer (1972), Sperber and Wilson (1995), D'Andrade (1987:113), Searle (1995:23-26), Schegloff (1996:459), Barr and Keysar (2004). Although analysts agree that humans can construct and consult common ground in interaction, there is considerable disagreement as to how pervasive it is (see discussion in Barr and Keysar 2004).

2. By hypothesis, I do not mean that we need consciously or explicitly entertain candidate accounts for questions like whether our colleagues will wear clothes to work tomorrow, or whether the sun will come up, or whether we will stop feeling thirsty after we have had a drink (saying "Aha, just as I suspected" when verified). But we nevertheless have models of how things are, which, most importantly, are always accessible, and become visible precisely when things go against our expectations (Whorf 1956). In order for this to work, we need some kind of stored representation, whether mental or otherwise embodied, which accounts for our expectations.

3. Steve Levinson points out the relevance of the great spatial distance between BW and the basket. Her reach has a long way to go when FW acts on the inference derived from observing her action. It may be that BW's stylized reach was overtly communicative, designed to induce recognition of intention, and the perlocutionary effect of causing FW to pass the basket (functioning, effectively, as a request).

4. The phrasing appropriates Slobin's thinking-for-speaking idea: that "language directs us to attend-while speaking-to the dimensions of experience that are enshrined in grammatical categories" (Slobin 1996: 71).

5. There is some controversy as to the extent to which we do audience design and assume its having been done. By a frugal cognition view, audience design is heavily minimized, but all analytical positions acknowledge that highpowered inference must at the very least be available when required (Barr and Keysar 2004; cf. Goodwin 2006, Hutchins 2006, Danziger 2006).

6. This is the corollary of the impossibility of pretending to possess common ground when you do not: witness the implausibility of fictional stories in which characters assume other characters' identities and impersonate them, living their lives without their kin and closest friends detecting that they are imposters (e.g., the reciprocal face transplant performed on arch enemies Castor Troy and Sean Archer in Face/Off, Paramount Pictures, 1997).

7. More work is needed to understand how the use of profanities works to display and constitute "close" social relations. Presumably, the mechanism is that "we can't talk like that with everybody." So, it is not a question of the symbolic content of the information being exchanged, but its register, its format. Compare this with more sophisticated ways of displaying social affiliation in the animal world, such as the synchronized swimming and diving that closely affiliated porpoises employ as a display of alliance 


\section{Nicholas J. Enfield}

(Connor et al. 2000:104). It is not just that these individuals are swimming together, but, in addition, how they are doing it.

8. Like the others in this list of names, Duang is socially "lower" than both the participants, and accordingly, her name is prefixed with the female nonrespect prefix qiil-; cf. Enfield (2007a, b).

9. I gratefully acknowledge the contribution of Manny Schegloff and Tanya Stivers to my understanding of this example.

10. The Lao word vang refers to a river pool, a section of river in which the water is deep and not perceptibly flowing, usually with thick forest towering over it, producing a slightly spooky atmosphere, of the kind associated with spirit owners (i.e., ghosts or spirits that "own" a place, and must be appeased when traveling through; see Enfield 2008). The same place is also called Faaj Vang Phêêng (faaj means "weir"; the deep still water of Vang Phêêng is a weir reservoir).

11. Vertically aligned square brackets indicate overlap in speech.

12. This is comparable with the use of him in the opening words of Paul Bremer's highly anticipated announcement at a Baghdad news conference in December 2003 of the capture of Saddam Hussein: "Ladies and gentlemen, we got him."

\section{References}

Baron-Cohen, Simon

1995. Mindblindness: An essay on autism and Theory of Mind. Cambridge, MA: MIT Press.

Barr, Dale J., and Boaz Keysar

2004 Making sense of how we make sense: The paradox of egocentrism in language use. In Figurative language processing: Social and cultural influences. Herb Colston and Albert Katz (eds.), 21-41. Mahwah, NJ: Erlbaum.

Buys, Christian J., and Kenneth L. Larson

1979 Human sympathy groups. Psychology Reports 45:547-553.

Carruthers, Peter and Peter K. Smith (eds.).

1996 Theories of Theories of Mind. Cambridge: Cambridge University Press.

Clark, Herbert H

1996 Using language. Cambridge: Cambridge University Press.

Cohen, Dov

1999 Adding insult to injury: Practices of empathy in an infertility support group. Ph.D. diss. School of Communication, Rutgers University. 
Connor, Richard C., Randall S. Wells, Janet Mann, and Andrew J. Read 2000 The Bottlenose Dolphin: Social relationships in a fission-fusion society. In Cetacean societies: Field studies of dolphins and whales. Janet Mann, Richard C. Connor, Peter L. Tyack, and Hal Whitehead (eds.), 91-126. Chicago: Chicago University Press.

D'Andrade, Roy D.

1987 A Folk Model of the Mind. In Cultural models in language and thought. Dorothy Holland and Naomi Quinn (eds.), 112-148. Cambridge: Cambridge University Press.

Drew, Paul, and Kathy Chilton

2000 Calling just to keep in touch: Regular and habitualised telephone calls as an environment for small talk. In Small Talk. J. Coupland (ed.), 137-162. Harlow: Pearson Education.

Dunbar, Robin I. M.

1993 Coevolution of neocortical size, group size, and language in humans. Behavioral and Brain Sciences 16:681-735.

1996 Grooming, gossip and the evolution of language. London: Faber and Faber.

1998 The social brain hypothesis. Evolutionary Anthropology 6:178-190.

Dunbar, Robin I. M., and M. Spoors

1995 Social networks, support cliques, and kinship. Human Nature 6:273290.

Enfield, Nicholas J.

2002 Cultural logic and syntactic productivity: Associated posture constructions in Lao. In Ethnosyntax: Explorations in culture and grammar. Nicholas J. Enfield (ed.), 231-258. Oxford: Oxford University Press.

2003 The definition of what-d'you-call-it: Semantics and pragmatics of recognitional deixis. Journal of Pragmatics 35:101-117.

2005 The body as a cognitive artifact in kinship representations. Hand gesture diagrams by speakers of Lao. Current Anthropology 46(1):51-81.

2006 Evidential interrogative particles in Lao. (Typescript) Language and Cognition Group, MPI Nijmegen, March 2006.

2007a Meanings of the unmarked: how 'default' person reference does more than just refer. In Person reference in interaction. Nicholas $\mathrm{J}$. Enfield and Tanya Stivers (eds.), 97-120. Cambridge: Cambridge University Press.

2007b A grammar of Lao. Berlin: Mouton de Gruyter.

2008 Linguistic categories and their utilities: the case of Lao landscape terms. Language Sciences, 30.2/3, 227-255. 


\section{Nicholas J. Enfield}

Enfield, Nicholas J., and Tanya Stivers (eds.).

2007 Person reference in interaction: Linguistic, cultural, and social perspectives. Cambridge: Cambridge University Press.

Fox, Barbara A.

1987 Discourse structure and anaphora: Written and conversational English. Cambridge: Cambridge University Press.

Garfinkel, Harold, and Harvey Sacks

1970 On formal structures of practical actions. In Theoretical sociology: Perspectives and developments. John C. McKinney and Edward A. Tiryakian (eds.), 337-366. New York: Meredith.

Gigerenzer, Gerd, Peter M. Todd, and The ABC Research Group

1999 Simple heuristics that make us smart. Oxford: Oxford University Press.

Goffman, Erving

1967 Interaction ritual. New York: Anchor Books.

1971 Relations in public. New York: Harper \& Row.

1981 Reprint. Forms of talk. Philadelphia: University of Pennsylvania Press. 1976.

Goodwin, Charles

1994 Professional vision. American Anthropologist 96(3):606-633.

1996 Transparent vision. In Interaction and grammar. Elinor Ochs, Emanuel A. Schegloff, and Sandra A. Thompson (eds.), 370-404. Cambridge: Cambridge University Press.

2000 Action and embodiment within situated human interaction. Journal of Pragmatics 32:1489-1522.

Goody, Esther N.(ed.).

1995 Social intelligence and interaction: Expressions and implications of the social bias in human intelligence. Cambridge: Cambridge University Press.

Grice, H. Paul

1975 Logic and conversation. In Speech acts. Peter Cole and Jerry L. Morgan (eds.). 41-58. New York: Academic Press.

1989 Studies in the way of words. Cambridge, MA: Harvard University Press.

Heritage, John, and J. Maxwell Atkinson

1984 Introduction. In Structures of social action: Studies in conversation analysis. J. Maxwell Atkinson and John Heritage (eds.), 1-15.

Cambridge: Cambridge University Press.

Hill, R. A., and Robin I. M. Dunbar

2003 Social network size in humans. Human Nature 14:53-72.

Hutchins, Edwin

1995 Cognition in the wild. Cambridge, MA: MIT Press. 
Hutchins, Edwin, and Brian Hazlehurst

1995 How to invent a shared lexicon: The emergence of shared formmeaning mappings in interaction. In Social intelligence and interaction: Expressions and implications of the social bias in human intelligence. Esther Goody (ed.), 53-67. Cambridge: Cambridge University Press.

Hutchins, Edwin, and Leysia Palen

1993 Constructing meaning from space, gesture, and speech. In Discourse, tools, and reasoning: Essays on situated cognition. Lauren B. Resnick, Roger Säljö, Clotilde Pontecorvo, and Barbara Burge (eds.), 23-40. Berlin: Springer-Verlag.

Jefferson, Gail

1974 Error Correction as an Interactional Resource. Language in Society 2:181-199.

1978 Sequential aspects of storytelling in conversation. In Studies in the organization of conversational interaction. J. Schenkein(ed.), 219248. New York: Academic Press.

Jefferson, Gail, and John R. E. Lee

1980 End of Grant Report to the British Ssrc on the analysis of conversations in which "troubles" and "anxieties" are expressed. Ref. Hr 4802. Manchester: University of Manchester.

Kita, Sotaro. (ed.)

2003 Pointing: Where language, cognition, and culture meet. Mahwah, NJ: Erlbaum.

Kockelman, Paul

2005 The semiotic stance. Semiotica 157:233-304.

Lerner, Gene $\mathrm{H}$.

1992 Assisted storytelling: Deploying shared knowledge as a practical matter. Qualitative Sociology 15:24-77.

1996 On the "semi-permeable" character of grammatical units in conversation: Conditional entry into the turn space of another speaker. In Interaction and grammar. Elinor Ochs, Emanuel A. Schegloff, and Sandra A. Thompson (eds.), 238-276. Cambridge: Cambridge University Press.

Levinson, Stephen C.

1995 Interactional biases in human thinking. In Social intelligence and interaction: Expressions and implications of the social bias in human intelligence. Esther Goody (ed.), 221-260. Cambridge: Cambridge University Press.

1997 From outer to inner space: Linguistic categories and non-linguistic thinking. In Language and conceptualization. Jan Nuyts and Eric Pederson (eds.), 13-45. Cambridge: Cambridge University Press. 
2000 Presumptive meanings: The theory of generalized conversational Lewis, David K. implicature. Cambridge, MA: MIT Press.

1969 Convention: A philosophical study. Cambridge, MA: Harvard University Press.

Mandelbaum, Jennifer

1987 Couples sharing stories. Communication Quarterly 352:144-170.

Maynard, Douglas W., and Don Zimmerman

1984 Topical talk, ritual, and the social organization of relationships. Social Psychology Quarterly 47:301-316.

Mead, George $\mathrm{H}$.

1934 Mind, Self, and Society from the Standpoint of a Social Behaviorist. Miller, Geroge A. Charles W. Morris (ed.), Chicago: University of Chicago Press.

1951 Language and communication. New York: McGraw-Hill.

Molder, Hedwig te, and Jonathan Potter (eds.)

2005 Conversation and Cognition. Cambridge: Cambridge University Press.

Moore, Chris, and Philip Dunham (eds.)

1995 Joint attention: Its origins and role in development. Hillsdale, NJ: Erlbaum.

Morrison, $\mathbf{J}$

1997 Enacting involvement: Some conversational practices for being in relationship. Ph.D. diss. School of Communications, Temple University.

Nettle, Daniel

1999 Language variation and the evolution of societies. In The evolution of culture: An interdisciplinary view. Robin I. M. Dunbar, Chris Knight, and Camilla Power (eds.), 214-227. New Brunswick, NJ: Rutgers University Press.

Nettle, Daniel, and Robin I. M. Dunbar

1997 Social markers and the evolution of reciprocal exchange. Current Anthropology 38(1):93-99.

Norman, Donald A.

1991 Cognitive artifacts. In Designing interaction: Psychology at the human-computer interface. John M. Carroll (ed.), 17-38. Cambridge: Cambridge University Press.

Peirce, Charles S.

1965 Reprint Collected papers of Charles Sanders Peirce, vol. 2. Elements of Logic. Charles Hartshorne and Paul Weiss (eds.), Cambridge, MA: Belknap Press of Harvard University Press. 1932. 
Pomerantz, Anita, and Jennifer Mandelbaum

2005 Conversation analytic approaches to the relevance and uses of relationship categories in interaction. In Handbook of language and social interaction, K. L. Fitch and R. E. Sanders (eds.), 149-171. Mahwah, NJ: Erlbaum.

Rogoff, Barbara

1994 Apprenticeship in thinking: Cognitive development in social context. New York: Oxford University Press.

Sacks, Harvey

1974 An analysis of the course of a joke's telling in conversation. In Explorations in the ethnography of speaking. Richard Bauman and Joel Sherzer (eds.), 337-353. Cambridge: Cambridge University Press.

1992 Lectures on conversation. London: Blackwell.

Sacks, Harvey, and Emanuel A. Schegloff

1979 Two preferences in the organization of reference to persons in conversation and their interaction. In Everyday language: Studies in ethnomethodology. George Psathas (ed.), 15-21. New York: Irvington.

Schank, Roger C., and Robert P. Abelson

1977 Scripts, plans, goals, and understanding: An inquiry into human knowledge structures. Hillsdale, NJ: Erlbaum.

Schegloff, Emanuel A.

1972 Notes on a conversational practice: Formulating place. In Studies in social interaction. D. Sudnow(ed.), 75-119. New York: The Free Press.

1982 Discourse as an interactional achievement: Some uses of "Uh Huh" and other things that come between sentences. In Georgetown University Roundtable on Languages and Linguistics 1981; Analyzing Discourse: Text and Talk, Deborah Tannen (ed.), 71-93. Washington, DC: Georgetown University Press.

1992 Repair after next turn: The last structurally provided defense of intersubjectivity in conversation. American Journal of Sociology 97(5): 1295-1345.

1996 Some practices for referring to persons in talk-in-interaction: A partial sketch of a systematics. In Studies in anaphora. B. Fox (ed.), 437-485. Amsterdam: John Benjamins.

1997 Third turn repair. In Towards a social science of language, vol. 2: Social interaction and discourse structures. G. R. Guy, C. Feagin, D. Schiffrin, and J. Baugh(eds.), 31-40. Amsterdam: John Benjamins.

2002 Tutorial on membership categorization devices. To appear in Issues in Conversation Analysis._M. F. Nielsen and J. Wagner (eds.). 


\section{Nicholas J. Enfield}

2007 Conveying who you are: The presentation of self, strictly speaking. In Person reference in interaction. N. J. Enfield and T. Stivers (eds.).

Schelling, Thomas C.

1960 The strategy of conflict. Cambridge, MA: Harvard University Press. 1978 Micromotives and macrobehavior. New York: W. W. Norton.

Schiffer, Stephen R.

1972 Meaning. Oxford: Clarendon Press.

Schutz, Alfred

1970 On phenomenology and social relations. Chicago: University of Chicago Press.

Searle, John R.

1995 The construction of social reality. New York: Free Press.

Slobin, Dan

1996 From "thought and language" to "thinking for speaking." In

Rethinking linguistic relativity. John J. Gumperz and Stephen C.

Levinson (eds.), 70-96. Cambridge: Cambridge University Press.

Smith, Neil V. (ed.)

1980 Mutual knowledge. London: Academic Press.

Sperber, Dan, and Diedre Wilson

1995 Relevance: Communication and cognition, 2nd edition. Oxford: Blackwell.

Sugawara, Kazuyoshi

1984 Spatial proximity and bodily contact among the Central Kalahari San. African Study Monograph (supp.) 3:1-43.

Tomasello, Michael

1999 The cultural origins of human cognition. Cambridge, MA: Harvard University Press.

Vygotsky, Lev S.

1962 Reprint. Thought and language. Cambridge, MA: MIT Press. 1934.

Whorf, Benjamin L.

1956 Language, thought, and reality. Cambridge, MA: MIT Press. 